${ }^{1}$ Chair of Dental Materials, Faculty of Dentistry, University of the Republic, Montevideo, Department of Montevideo, Uruguai.

${ }^{2}$ Department of Dental Materials, School of Dentistry, Federal University of Rio Grande do Sul, Porto Alegre, RS, Brazil.
Corresponding author:

Fabrício Mezzomo Collares Department of Dental Materials, School of Dentistry, Federal University of Rio Grande do Sul. Ramiro Barcelos Street, 2492, Rio Branco, 90035-003, Porto Alegre, RS, Brazil.

fabricio.collares@ufrgs.br

Phone number: +55 5133085198

Received: June 22, 2020

Accepted: September 25, 2020

\section{Surface and mechanical properties of adhesives with calcium phosphates challenged to different storage media}

Marcelo Matias Mederos Gómez ${ }^{1}$ iD, Isadora Martini Garcia² $^{\text {ID }}$, Vicente Castelo Branco Leitune ${ }^{2}$ iD, Fabrício Mezzomo Collares ${ }^{2, *}$ iD

Aim: To evaluate the behavior of experimental dental adhesives with hydroxyapatite (HAp), alpha-tricalcium phosphate ( $\alpha$-TCP) or octacalcium phosphate (OCP) after storing them in three different media: dry storage, distilled water, or lactic acid. Methods: An experimental adhesive resin was formulated with bisphenol A glycol dimethacrylate, 2-hydroxyethyl methacrylate, and photoiniciator/co-initiator system. HAp $\left(G_{\text {HAp }}\right), \alpha-T C P$ $\left(G_{a-T C P}\right)$, or OCP $\left(G_{O C P}\right)$ were added to the adhesive resin at 2 wt.\%, and one group remained without calcium phosphates to be used as a control $\left(\mathrm{G}_{\mathrm{ctrr}}\right)$. The adhesives were evaluated for surface roughness, scanning electron microscopy (SEM), and ultimate tensile strength (UTS) after storing in distilled water $(\mathrm{pH}=5.8)$, lactic acid $(\mathrm{pH}=4)$ or dry medium. Results: The initial surface roughness was not different among groups ( $p>0.05$ ). $G_{\text {HAp }}$ showed increased values after immersion in water $(p<0.05)$ or lactic acid $(p<0.05)$. SEM analysis showed a surface variation of the filled adhesives, mainly for $G_{a-T C P}$ and $G_{\text {HAP }}$. $G_{\text {HAP }}$ showed the highest UTS in dry medium $(p<0.05)$, and its value decreased after lactic acid storage $(p<0.05)$. Conclusions: The findings of this study showed that HAp, OCP, and $\alpha-T C P$ affected the physical behavior of the experimental adhesive resins in different ways. HAp was the calcium phosphate that most adversely affected the surface roughness and the mechanical property of the material, mainly when exposed to an acid medium.

Keywords: Dentin-bonding agents. Calcium phosphates. Acids. Polymers. Tensile strength. 


\section{Introduction}

Recurrent caries at the tooth-restoration interface is one of the major causes of restoration replacement over time ${ }^{1}$. This outcome is related to materials' hydrolytic and enzymatic degradation when in contact with the oral environment, leading to higher surface roughness, biofilm accumulation at the margin, and caries development ${ }^{2}$. Moreover, restorative materials may not completely seal the tooth interface. Mainly over time, the sealing ability still is a concern since gaps are prone to caries development $^{3}$. Restorative resin-based materials have been modified to decrease polymerization shrinkage, hydrolysis degradation, and to decrease gaps formation at the interface via a biomimetic remineralization approach4

Bioactive fillers have been added to resins to provide them bioactivity with the ultimate purpose of reducing the incidence of caries around the restoration's margin. Calcium orthophosphates (CaP) are the most representative fillers able to release calcium and phosphate ions, which are retained in the oral biofilm and induce dental remineralization ${ }^{5-8}$. CaP present different molecular forms, crystalline structures, and solubility values ${ }^{9,10}$. Previous studies evaluated $\mathrm{CaP}$ as fillers in experimental adhesive resins showing promising results such as increased bond strength ${ }^{11,12}$ and mineral deposition at the tooth $6,8,11$.

Currently, studies that evaluate ion-releasing bioactive materials, such as those filled with bioglasses and CaP, stored them in water ${ }^{13,14}$, ethano ${ }^{13}$, artificial saliva ${ }^{15}$ or simulated body fluid ${ }^{5}$. However, the release of ions may increase materials' roughness over time ${ }^{16}$, especially when they are exposed to acid medium, which could occur in the presence of an acidogenic biofilm ${ }^{17}$. The results of a recent in vitro study suggest that low $\mathrm{pH}$ increases the surface roughness and alter the superficial topography of resin-based orthodontic adhesives $^{18}$. The change in the roughness may indicate modifications not only in the morphology of the material but also in its chemical and physical stability ${ }^{1920}$. The bioactive material must maintain its mechanical and chemical properties to seal the cavity adequately ${ }^{21}$.

In a previous study, the authors formulated an experimental adhesive resin composed of bisphenol A glycol dimethacrylate, 2-hydroxyethyl methacrylate, and a photoinitiator/co-initiator system ${ }^{11}$. The material was filled with different calcium orthophosphates at 2 wt.\%: hydroxyapatite $\left(\mathrm{HAp} ; \mathrm{Ca}_{5}\left(\mathrm{PO}_{4}\right)_{3}(\mathrm{OH})\right)$, alpha-tricalcium phosphate $\left(\alpha\right.$-TCP; $\left.\mathrm{Ca}_{3}\left(\mathrm{PO}_{4}\right)_{2}\right)$, or octacalcium phosphate (OCP; $\left.\mathrm{Ca}_{8} \mathrm{H}_{2}\left(\mathrm{PO}_{4}\right)_{6} 5 \mathrm{H}_{2} \mathrm{O}\right)^{11}$. The filled adhesives were compared to the base resin without $\mathrm{CaP}$ (control group), and they showed a higher degree of conversion. Furthermore, the $\alpha$-TCP group showed a high microshear bond strength compared with the other groups. The $\alpha$-TCP and HAp groups induced mineral deposition at the tooth-resin interface, suggesting that these fillers could be an alternative to formulate bioactive dental resins.

Despite these findings, the effect of different storage media on the behavior of adhesives composed of $\alpha-T C P, H A p$, or OCP was not investigated so far. The aim of this study was to evaluate the behavior of experimental adhesive resins with HAp, $\alpha-T C P$, or OCP after storing them in three different storage media. The null hypotheses to be tested are: (1) there are no differences among the adhesives formulated with different CaP regarding their surface and mechanical properties; (2) different storage media do not influence the surface and mechanical properties of the adhesives. 


\section{Materials and Methods}

In this study, the dependent variables analyzed are surface roughness, surface morphology, and ultimate tensile strength. Two independent variables were analyzed: (1) the variable "addition of CaP", with four different adhesives composed solely by the base resin or with 2 wt.\% of hydroxyapatite (HAp), alpha-tricalcium phosphate $(\alpha-T C P)$, or octacalcium phosphate (OCP); (2) the variable "storage medium", in which the adhesives were immersed: dry storage, distilled water, or acidic solution (Figure 1).

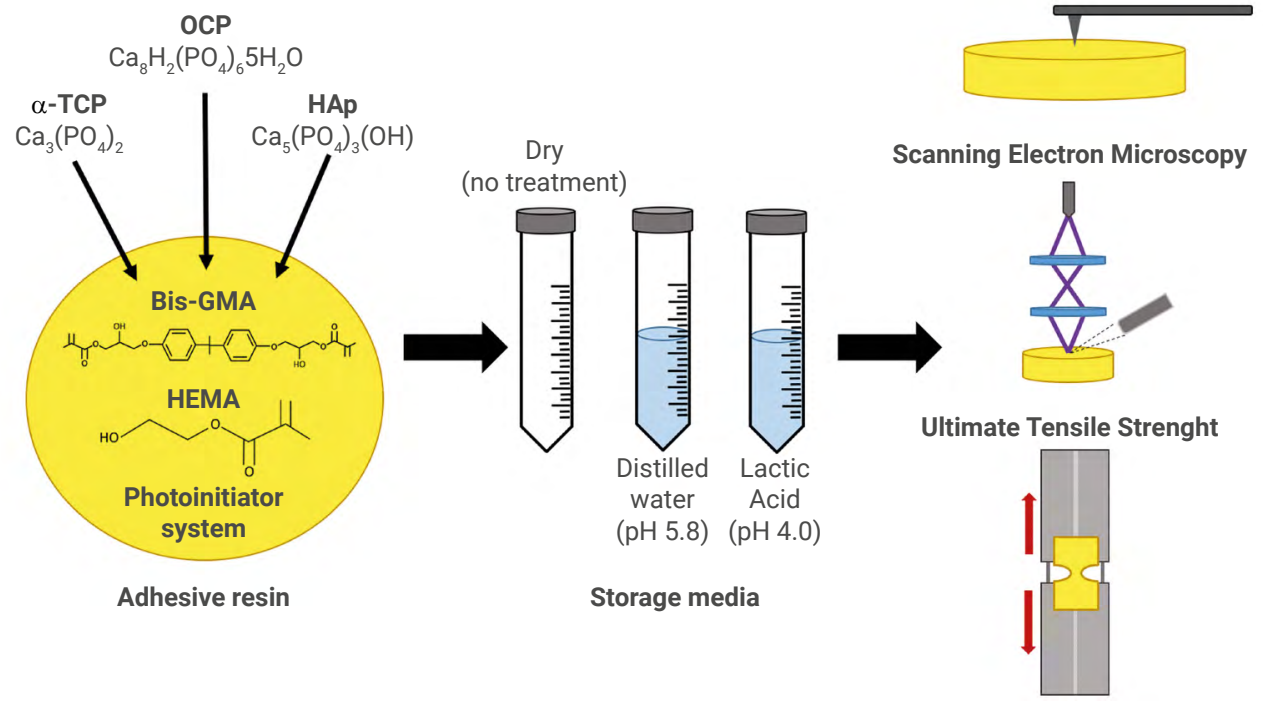

Figure 1. Representative illustration that summarizes the materials and methods of the study.

\section{Experimental Adhesive Resin Formulation}

The experimental adhesive resin was formulated mixing 66.66 wt.\% bisphenol A glycol dimethacrylate and 33.33 wt.\% 2-hydroxyethyl methacrylate. Camphorquinone and ethyl 4-(dimethylamino) benzoate were added as a photoinitiator system at 1 mol\%. Butylated hydroxytoluene was added at $0.01 \mathrm{wt} \%$ as polymerization inhibitor. These reagents were purchased from Aldrich Chemical, St Louis, MO, USA. Three CaP were previously synthesized, and they were added in this base resin at $2 \mathrm{wt} . \%$ : $\alpha$-TCP $\left(\mathrm{G}_{\mathrm{a}-\mathrm{TCP}} 6.03 \mu \mathrm{m}\right)^{22}$, OCP $\left(\mathrm{G}_{\mathrm{OCP}} 4.94 \mathrm{~nm}\right)^{23}$ and HAp $\left(\mathrm{G}_{\mathrm{HAP}}, 26.7 \mathrm{~nm}\right)^{24}$. A group without $\mathrm{CaP}$ was used as control $\left(\mathrm{G}_{\mathrm{Ctr}}\right)$, totaling four groups. The mixture (resin/particles) was hand-mixed for $5 \mathrm{~min}$, sonicated for $180 \mathrm{~s}$, and hand-mixed again for $5 \mathrm{~min}$.

\section{Surface Roughness (Ra)}

Five samples per group were prepared (10 mm diameter $X 1 \mathrm{~mm}$ thickness) using a polyvinylsiloxane mold. The uncured adhesive resins were inserted in the molds between two transparent Mylar strips. The samples were light-cured for $30 \mathrm{~s}$ on each side (Radii Cal, SDI; Bayswater, Victoria, Australia, $1200 \mathrm{~mW} / \mathrm{cm}^{2}$ ). The top of each 
sample was marked and divided in half. Four measurements of surface roughness were performed immediately on one half using a profilometer (Mitutoyo, Surftest SJ-201P, Chicago, USA) with a tracing length of $2 \mathrm{~mm}$ and $0.25 \mathrm{~mm}$ cut-off. Then, each sample was submerged and stored in individual-hermetic containers for 3 days at $37^{\circ} \mathrm{C}^{17}$, in $10 \mathrm{~mL}^{25,26}$ of different media as distilled water or lactic acid with $\mathrm{pH}$ at 5.8 and $4^{17}$, respectively. The samples were placed vertically so that the surfaces to be tested were kept exposed to the different media. The $\mathrm{pH}$ of these media was evaluated along with the study via a digital pH meter (DM-22, Digimed, São Paulo, SP, Brazil). After 3 days of storage, four new measurements were performed on the other half on the top of each sample. The initial roughness (Ra1), final roughness (Ra2), and roughness variation $(\Delta \mathrm{Ra})$ were recorded for each group.

\section{Surface morphology via scanning electron microscopy (SEM)}

The surface morphology of three samples per group used in the roughness assessment (stored in distilled water and lactic acid) was evaluated via SEM. Other three samples per group were prepared and stored in a dry environment inside a desiccator with silicon dioxide at $37{ }^{\circ} \mathrm{C}$ for 3 days to be also analyzed via SEM. The samples were placed on metallic stubs and gold-sputter coated (15-25 nm) (SDC 050, Baltec, Vaduz, Liechtenstein). SEM analysis (SEM, JSM 6060, JEOL, Tokyo, Japan) was performed under $7 \mathrm{kV}$, at 5,000' and 8,000' magnification.

\section{Ultimate Tensile Strength (UTS)}

Thirty samples per group were prepared in a metallic matrix with an hourglass shape ( $8 \mathrm{~mm}$ long, $2 \mathrm{~mm}$ wide, $1 \mathrm{~mm}$ thickness, and $1 \mathrm{~mm}^{2}$ at constriction area) after photoactivation for $30 \mathrm{~s}$ on each side ${ }^{27}$. After photoactivation, the samples were measured with a digital caliper (Mitutoyo, Kawasaki, Kanagawa, Japan; accuracy of $10 \mu \mathrm{m}$ ) to obtain the constriction area of each one. Then, the thirty samples from each group were divided and submerged into $1 \mathrm{~mL}$ of the three media of storage $(n=10$, dry environment in a desiccator, distilled water, or lactic acid) to be sat for 3 days at $37^{\circ} \mathrm{C}$. The specimens were fixed in metallic jigs with cyanoacrylate resin to be tested for tensile strength. The tests were performed in a universal testing machine (EZ Test EZ-SX, Shimadzu, Japan) at a crosshead speed of $1 \mathrm{~mm} / \mathrm{min}$. The values were obtained in newtons, and the final UTS was expressed in megapascals (MPa) using the constriction area of each sample.

\section{Statistical Analysis}

The data were analyzed using the software SigmaPlot $\AA$, version 12.0 (Systat Software, Inc., San Jose, CA, USA). Data distribution was evaluated using the Shapiro-Wilk test. One-way analysis of variance (ANOVA) was used to compare groups for initial surface roughness. Paired t test was used for each group to evaluate the difference between immediate and final surface roughness. Kruskal-Wallis was used to compare $\Delta \mathrm{Ra}$ among groups in both media, and Dunn's was used as post-hoc after immersion in lactic acid. Two-way ANOVA was used to compare groups for UTS dry medium, distilled water or lactic acid. A significance level of 0.05 was considered. 


\section{Results}

The results of surface roughness before (Ra1) and after (Ra2) immersion of the experimental adhesive resins, as well as the $\Delta \mathrm{Ra}$, in distilled water and in lactic acid are shown in Table 1. The authors did not perform other statistical analysis such as threeway ANOVA, split-plot two-way ANOVA, or two-way ANOVA with repeated measures to analyze this data because there is a dependency within the same group (the same group was tested before and after the storage in the liquids). Moreover, the samples tested for immersion in water or lactic acid are not the same since this is a destructive method and the same sample could not be immersed in both liquids one after the other. Statistical analysis with repeated measures considering different immersions (in water or lactic acid) should not be applied. In this context, the one-way ANOVA revealed no statistically significant differences among groups for Ra1 ( $p>0.05)$. After immersion in distilled water, $G_{\text {HAp }}$ roughness increased $(p<0.05)$, while the other groups showed no statistically significant differences ( $p>0.05$ ). Moreover, there was no difference among groups for $\Delta \mathrm{Ra}$ after immersion in water ( $p>0.05)$. On the other hand, the materials presented different behavior after immersion in lactic acid solution. While there was no difference among groups for Ra1 ( $p>0.05)$, the roughness of $G_{a-T C P}$ and $\mathrm{G}_{\text {HAP }}$ increased after immersion in lactic acid $(p<0.05)$ and $G_{C t r l}$ and $G_{O C P}$ had no differences between Ra1 and Ra2 ( $p>0.05)$. When comparing $\Delta$ Ra after immersion in lactic acid, $G_{\text {HAp }}$ showed the highest variation among groups, with statistical difference in comparison to $G_{C t r l}(p<0.05)$.

Table 1. Results of surface roughness of the experimental adhesive resins with different calcium phosphates before and after the immersion in distilled water or lactic acid.

\begin{tabular}{|c|c|c|c|c|c|c|}
\hline \multirow{3}{*}{ Group } & \multicolumn{3}{|c|}{ Storage in distilled water } & \multicolumn{3}{|c|}{ Storage in lactic acid } \\
\hline & $\begin{array}{l}\text { Roughness } \\
\text { before } \\
\text { immersion }\end{array}$ & $\begin{array}{l}\text { Roughness } \\
\text { after } \\
\text { immersion }\end{array}$ & $\Delta \mathrm{Ra}(\%)$ & $\begin{array}{l}\text { Roughness } \\
\text { before } \\
\text { immersion }\end{array}$ & $\begin{array}{l}\text { Roughness } \\
\text { after } \\
\text { immersion }\end{array}$ & $\Delta \operatorname{Ra}(\%)$ \\
\hline & $(\mathrm{Ra} 1, \mu \mathrm{m})$ & $(\mathrm{Ra} 2, \mu \mathrm{m})$ & & $(\mathrm{Ra} 1, \mu \mathrm{m})$ & $(\mathrm{Ra} 2, \mu \mathrm{m})$ & \\
\hline $\mathbf{G}_{\mathrm{Ctrl}}$ & $0.09( \pm 0.01)^{\mathrm{Aa}}$ & $0.12( \pm 0.05)^{a}$ & $47.93( \pm 70.28)^{A}$ & $0.11( \pm 0.04)^{\mathrm{Aa}}$ & $0.13( \pm 0.03)^{a}$ & $24.74( \pm 49.88)^{\text {в }}$ \\
\hline $\mathbf{G}_{\mathrm{OCP}}$ & $0.10( \pm 0.03)^{\mathrm{Aa}}$ & $0.15( \pm 0.07)^{a}$ & $59.35( \pm 76.50)^{A}$ & $0.10( \pm 0.04)^{\mathrm{Aa}}$ & $0.16( \pm 0.10)^{a}$ & $59.07( \pm 75.10)^{A B}$ \\
\hline $\mathbf{G}_{\mathrm{a}-\mathrm{TCP}}$ & $0.08( \pm 0.03)^{\mathrm{Aa}}$ & $0.13( \pm 0.03)^{a}$ & $78.85( \pm 97.40)^{\mathrm{A}}$ & $0.10( \pm 0.03)^{\mathrm{Aa}}$ & $0.21( \pm 0.06)^{b}$ & $116.94( \pm 83.58)^{A B}$ \\
\hline $\mathbf{G}_{\text {HAp }}$ & $0.07( \pm 0.01)^{\mathrm{Aa}}$ & $0.21( \pm 0.08)^{b}$ & $173.91( \pm 96.28)^{A}$ & $0.08( \pm 0.02)^{\mathrm{Aa}}$ & $0.30( \pm 0.06)^{b}$ & $285.64( \pm 110.34)^{A}$ \\
\hline
\end{tabular}

Different capital letters indicate statistically significant difference in the same column $(p<0.05)$.

Different small letters indicate statistically significant difference in the same row within the same medium of storage (distilled water or lactic acid) $(p<0.05)$.

The images from SEM analyses corroborate the findings of surface roughness measurement. Few differences can be observed in the surface of $\mathrm{G}_{\mathrm{ctrl}}$ between dry storage and distilled water storage (Figure $2 A-D$ ). Higher irregularities are identified for $\mathrm{G}_{\mathrm{Ctrl}}$ when it was stored in lactic acid (Figure $2 \mathrm{E}, \mathrm{F}$ ). As well as observed for $\mathrm{G}_{\mathrm{Ctr}}$, almost no differences are observed among images of dry storage and distilled water for $\mathrm{G}_{\mathrm{OCP}}$ (Figure $\left.3 \mathrm{~A}-\mathrm{D}\right)$. When exposed to lactic acid, more irregularities are observed (Figure $3 \mathrm{E}, \mathrm{F}$ ). Compared with $\mathrm{G}_{\mathrm{Ctrl}} \mathrm{G}_{\mathrm{OCP}}$ showed higher defects when exposed to 
lactic acid. The surface of $\mathrm{G}_{\mathrm{a}-\mathrm{TCP}}$ stored in distilled water, and lactic acid (Figure $4 \mathrm{C}-\mathrm{F}$ ) showed larger irregularities than $G_{C t r l}$. $G_{\text {HAP }}$ showed the highest difference on the surface between dry storage and distilled water storage (Figure $5 \mathrm{~A}-\mathrm{D}$ ) compared with $\mathrm{G}_{\mathrm{Ctrl}}, \mathrm{G}_{\mathrm{OCP},}$ and $\mathrm{G}_{\mathrm{a}-\mathrm{TCP}}$. In addition, after storing in lactic acid (Figure $5 \mathrm{E}, \mathrm{F}$ ), $\mathrm{G}_{\text {HAp }}$ presented higher irregularities, with larger cracks and cavities with irregular borders distributed on an irregular surface.

\section{Control group}
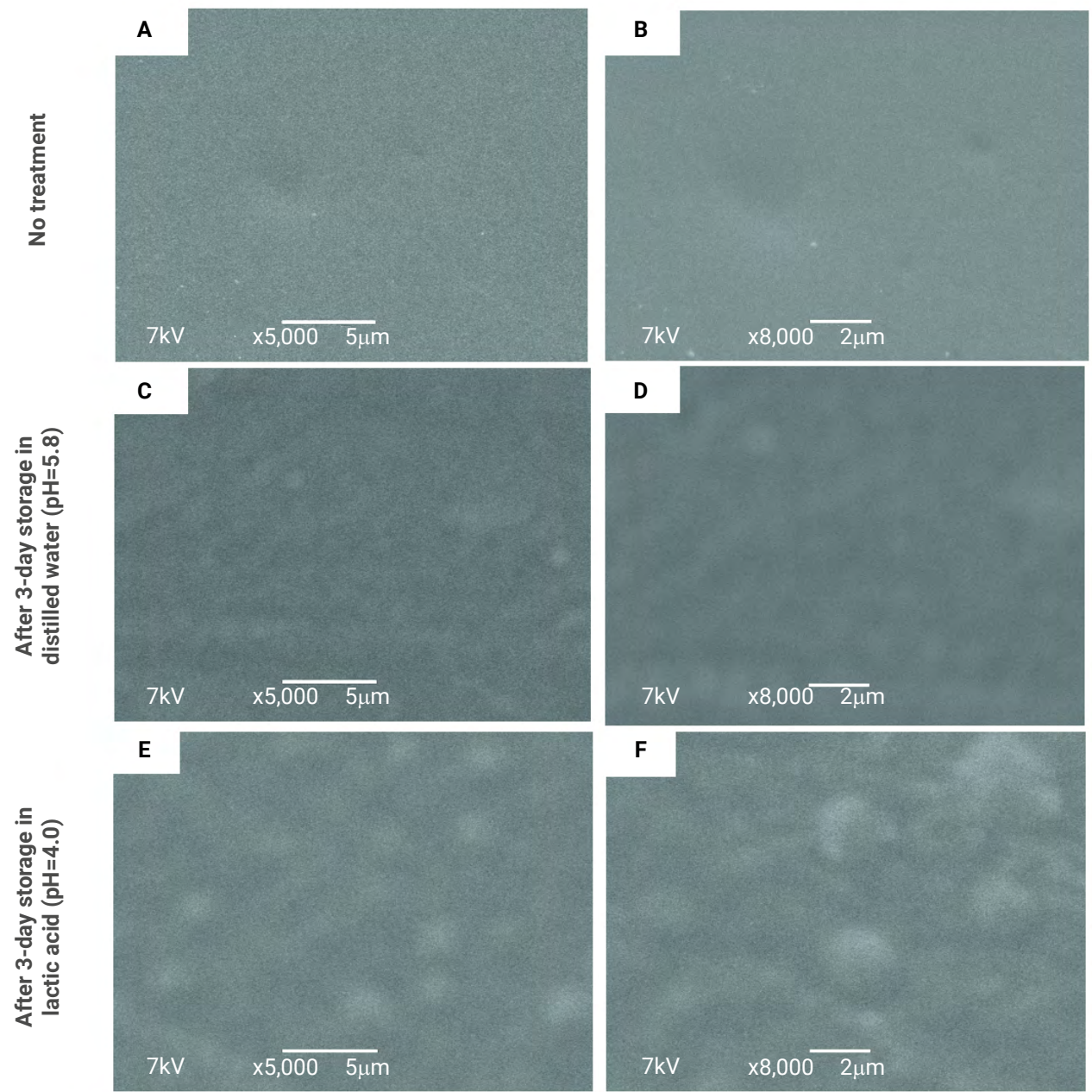

Figure 2. Scanning electron microscopy of $\mathrm{G}_{\mathrm{Ctrl}}$ at dry (no treatment), distilled water, or lactic acid storage. Few differences are observed for this group without calcium phosphates addition when the surface is exposed to dry storage ( $A$ and $B$ ) compared to that after water storage ( $C$ and $D)$. After the exposition to lactic acid, $\mathrm{G}_{\mathrm{Ctrl}}$ presents higher irregularities ( $\mathrm{E}$ and $\mathrm{F}$ ). 


\section{Octacalcium phosphate group}
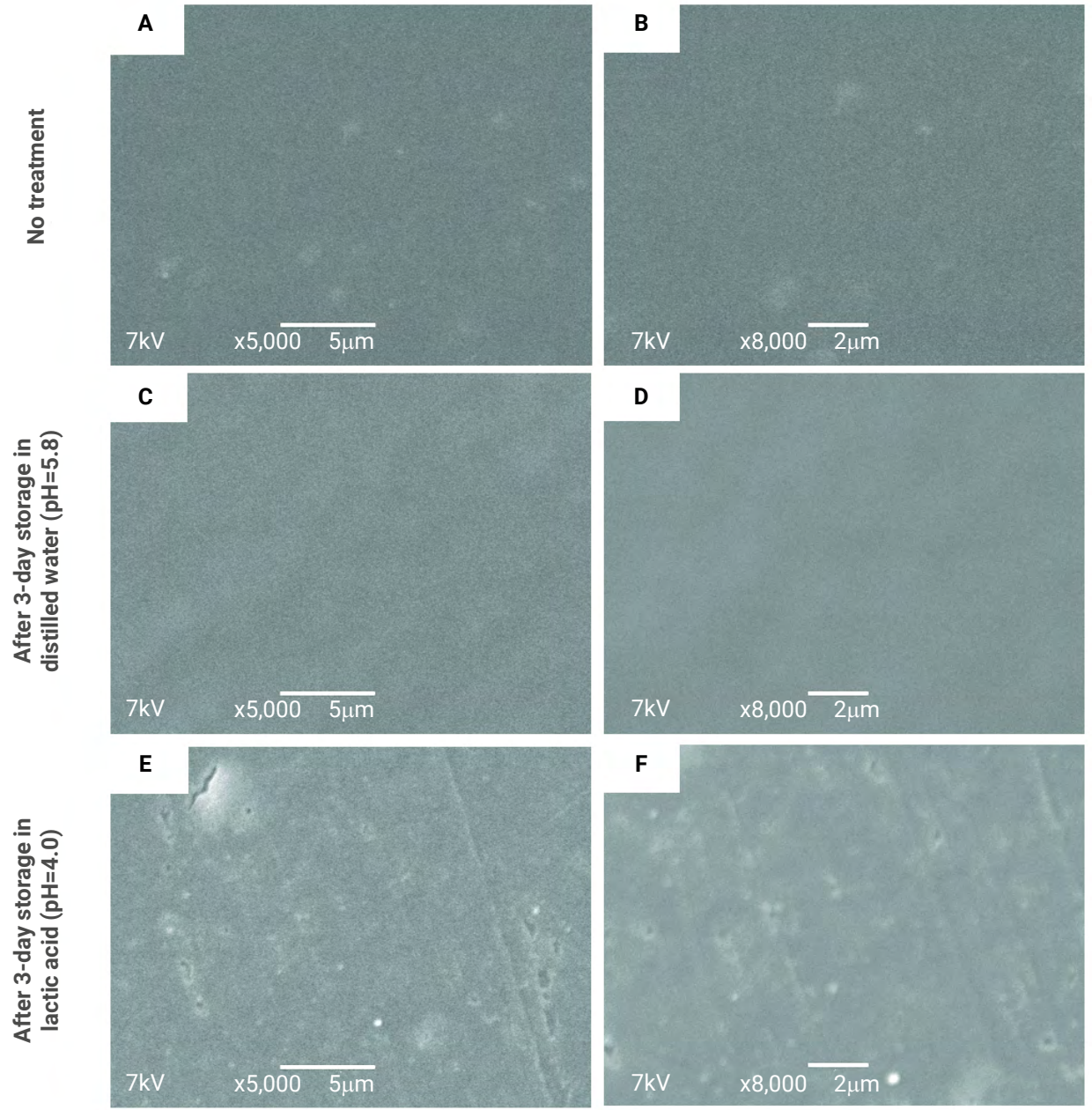

Figure 3. Scanning electron microscopy of $\mathrm{G}_{\mathrm{OCP}}$ at dry (no treatment), distilled water, or lactic acid storage. Few differences are observed for $G_{\text {cop }}$ when the surface is exposed to dry storage (A and $B$ ) compared to that after water storage $(C$ and $D)$. After the exposition to lactic acid, this group showed higher irregularities (E and F). 
Alpha-tricalcium phosphate group
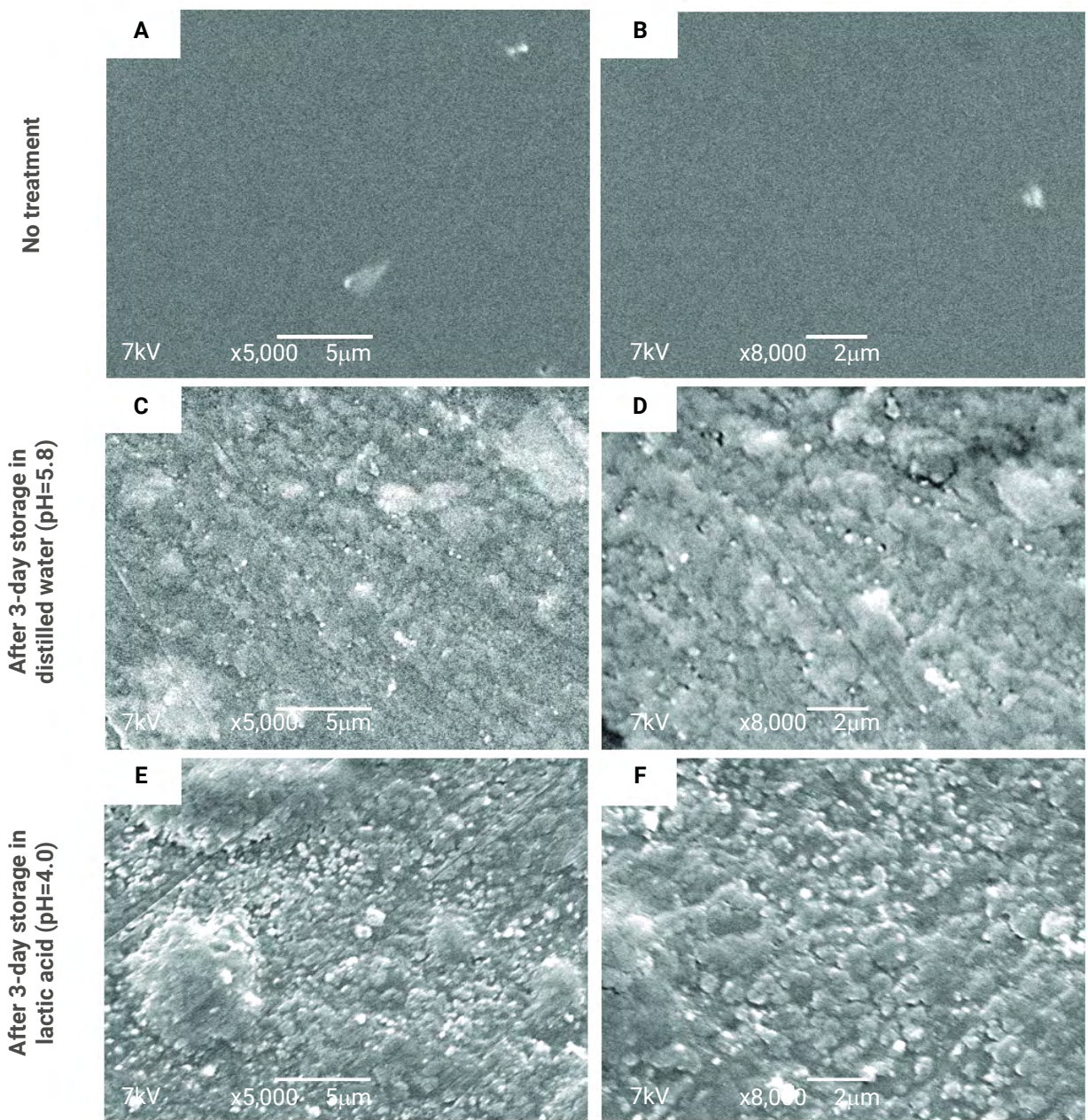

Figure 4. Scanning electron microscopy of $\mathrm{G}_{\mathrm{a}-\mathrm{TCP}}$ at dry (no treatment), distilled water, or lactic acid storage. High differences are observed within this group when "no treatment" ( $A$ and $B$ ) is compared to the surfaces after water ( $C$ and $D)$ or lactic acid ( $E$ and $F$ ) exposition. Observe that $G_{\text {a-TCP }}$ shows a much more irregular surface after water or lactic acid storage in comparison to $\mathrm{G}_{\mathrm{Ctrl}}$ and $\mathrm{G}_{\mathrm{OCP}}$. 
Hydroxiapatite group
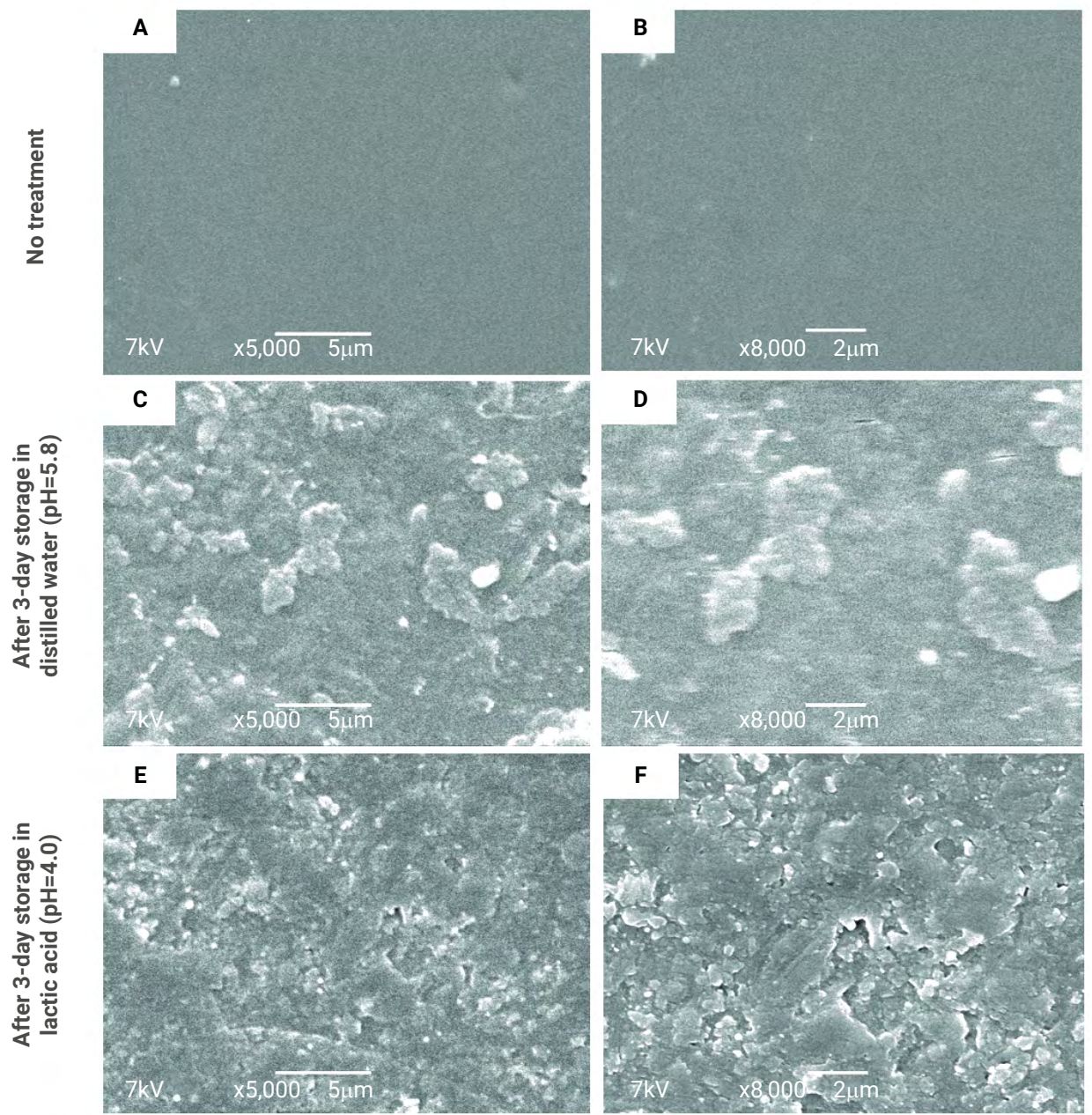

Figure 5. Scanning electron microscopy of $\mathrm{G}_{\text {HAD }}$ at dry (no treatment), distilled water, or lactic acid storage. High differences are observed within this group when "no treatment" (A and $B$ ) is compared to the surfaces after water ( $C$ and $D$ ) or lactic acid ( $E$ and $F$ ) exposition. Observe that, mainly after the lactic acid exposition, $\mathrm{G}_{\mathrm{HAP}}$ shows more irregularities than the other adhesive resins, areas with large cracks and cavities surrounded by irregular borders.

The results of the UTS of the experimental adhesive resins exposed to different media are shown in Table 2. After dry storage, the values ranged from $28.69( \pm 10.93) \mathrm{MPa}$ for $\mathrm{G}_{\mathrm{Ctrl}}$ to $46.34( \pm 10.72) \mathrm{MPa}$ for $\mathrm{G}_{\mathrm{HAp}}$, with a statistically significant difference between $G_{\text {Ctrl }}$ and $G_{\text {HAP }}(p<0.05)$. The values of UTS after distilled water storage ranged from $30.53( \pm 6.07) \mathrm{MPa}$ for $\mathrm{G}_{\mathrm{OCP}}$ to $39.26( \pm 9.44) \mathrm{MPa}$ for $\mathrm{G}_{\mathrm{Ctr},}$, without differences among groups ( $p>0.05)$. After lactic acid storage, the values of UTS ranged from $29.56( \pm 6.43)$ $\mathrm{MPa}$ for $\mathrm{G}_{\text {HAp }}$ to $33.87( \pm 11.93) \mathrm{MPa}$ for $\mathrm{G}_{\mathrm{Ctrl}}$ also without differences among groups $(p>0.05) . G_{\text {HAp }}$ was the only group that presented a statistically significant difference among the different storage media, with lower UTS values after lactic acid storage $(29.56 \pm 6.43 \mathrm{MPa})$ than dry medium $(46.34 \pm 10.72 \mathrm{MPa})(p<0.05)$. 
Table 2. Results of ultimate tensile strength of the experimental adhesive resins with different calcium phosphates after their storage in different media: dry, distilled water or lactic acid.

\begin{tabular}{lccc}
\hline Group & Dry $(\mathbf{M P a})$ & Water $(\mathrm{MPa})$ & Lactic Acid (MPa) \\
\hline $\mathbf{G}_{\mathrm{Ctrl}}$ & $28.69( \pm 10.93)^{\mathrm{Ba}}$ & $39.26( \pm 9.44)^{\mathrm{Aa}}$ & $33.87( \pm 11.93)^{\mathrm{Aa}}$ \\
\hline $\mathbf{G}_{\text {OCP }}$ & $35.96( \pm 17.19)^{\mathrm{ABa}}$ & $30.53( \pm 6.07)^{\mathrm{Aa}}$ & $32.61( \pm 6.93)^{\mathrm{Aa}}$ \\
\hline $\mathbf{G}_{\mathrm{a}-\mathrm{TCP}}$ & $34.43( \pm 11.48)^{\mathrm{ABa}}$ & $38.14( \pm 7.88)^{\mathrm{Aa}}$ & $30.36( \pm 13.22)^{\mathrm{Aa}}$ \\
\hline $\mathbf{G}_{\text {HAp }}$ & $46.34( \pm 10.72)^{\mathrm{Aa}}$ & $34.60( \pm 9.89)^{\mathrm{Aab}}$ & $29.56( \pm 6.43)^{\mathrm{Ab}}$ \\
\hline
\end{tabular}

Different capital letters indicate statistically significant difference in the same column $(p<0.05)$.

Different small letters indicate statistically significant difference in the same row $(p<0.05)$.

\section{Discussion}

Bioactive materials with ion-releasing fillers such as CaP have been investigated to induce the remineralization process of dental tissues ${ }^{7}$. Studying the behavior of bioactive materials when exposed to different media could assist in understanding their physical properties. In this study, adhesive resins with HAp, $\alpha$-TCP, or OCP were tested regarding their physical properties after storing in distilled water, lactic acid, or dry medium. There were significant differences among the adhesives with different $\mathrm{CaP}$, leading to the rejection of the first null hypothesis. Furthermore, the storage media influenced the behavior of the adhesives, which led us also to reject the second null hypothesis.

Dental materials are susceptible to suffering chemical and physical modifications in the oral environment due to hydrolysis and to bacterial enzymes, leading to their degradation over time ${ }^{28}$. High surface roughness contributes to the attachment of microorganisms and biofilm development ${ }^{28}$, besides making it more difficult to maintain hygiene ${ }^{28}$. In 1990, an in vivo study using fluorethylenepropylene or cellulose acetate strips suggested that the surface roughness of $\mathrm{Ra}=0.2 \mu \mathrm{m}$ was a threshold value for bacterial retention in intraoral surfaces ${ }^{29}$. Moreover, it is suggested that when the values are lower than $0.2 \mu \mathrm{m}$, the materials' chemical properties may be more important for biofilm formation than the surface roughness.

Currently, lower values up to $0.1 \mu \mathrm{m}$ are recommended for polishing resins with inorganic particles to reduce biofilm accumulation². $G_{a-T C P}$ and $G_{\text {HAp }}$ presented Ra higher than $0.2 \mu \mathrm{m}$ after immersing in lactic acid, and $G_{\text {HAp }}$ showed values above $0.2 \mu \mathrm{m}$ even after distilled water storage. In addition to inducing remineralization, ion-releasing materials have been suggested to inhibit biofilm formation by increasing the $\mathrm{pH}$ around them and delaying bacterial colonization ${ }^{30}$. However, the exposed CaP on the materials' surface, accompanied by the increase of surface roughness, was shown not to decrease bacterial adhesion ${ }^{17}$. In this study, as well as in the previous report ${ }^{17}$, the samples were not subject to $\mathrm{pH}$ cycles, which could lead to different results and, maybe, lower surface roughness differences. However, this method is a way to evaluate the material over an extreme situation.

Besides the surface roughness measurement, the surface morphology of the experimental adhesive resins was evaluated via SEM, which supported the results observed for Ra. In distilled water, $G_{\text {a-TCP }}$ and $G_{\text {HAP }}$ showed larger holes interspersed with small prominences on an irregular surface compared with $\alpha$-TCP or HAp in a dry medium. A uniform pattern over the entire surface of $G_{a-T C P}$ and $G_{H A p}$ was observed, probably due to a slight hydrolytic effect on the resin matrix ${ }^{31}$. After lactic acid storage, the variation 
of surface integrity was more pronounced for CaP groups than for $\mathrm{G}_{\mathrm{Ctrl}}$. This result corroborated the values found for $\Delta \mathrm{Ra}$, mainly for $\mathrm{G}_{\mathrm{HAp}}$, which should statistically significant difference for $G_{C t r l}$ after immersion in acid. We could also observe that the $G_{\text {ocp }}$ showed small grooves and holes scattered on the surface after lactic acid storage, while $G_{a-T C P}$ presented a similar pattern to $G_{a-T C P}$ immersed in distilled water but with cracks in greater quantity.

The group containing HAp showed larger cavities with irregular limits distributed over a slightly smooth surface. It is possible that these cavities were created due to the release of HAp agglomerates because low values of surface area were found for HAp previously synthesized by the same method ${ }^{24}$. Nanoparticles are prone to agglomeration due to their high surface energy. In composite resins, agglomerates of nanoparticles presented lower adhesion to the organic matrix compared with microparticles, detaching over time ${ }^{32}$. These agglomerates jeopardize the composite resins compared to microparticles, making the material more susceptible to mechanical failure and surface wear ${ }^{33}$. This process could occur with HAp in the experimental adhesive resin because the small molecules of lactic acid could diffuse through pores among HAp agglomerates and produce faster dissolution ${ }^{34}$.

In the mechanical analysis, the immediate UTS increased with HAp incorporation compared with $G_{\text {Ctrl }}$, without differences for $G_{a-T C P}$ and $G_{O C P}$. In distilled water, there were no differences in UTS, neither among groups nor between the same group comparing dry storage and distilled water storage. On the other hand, the mechanical performance was different after immersion in lactic acid solution, with $G_{\text {HAp }}$ showing reduced UTS compared with $\mathrm{G}_{\text {HAp }}$ in dry storage. This group also presented the highest surface roughness variation after exposure to the lactic acid solution. These results suggest that, even without statistically significant differences among $\mathrm{G}_{\mathrm{a}-\mathrm{TCP}} \mathrm{G}_{\text {HAP, }}$ and $\mathrm{G}_{\mathrm{OCP}}$ after storing in lactic acid, the UTS could be jeopardized for $\mathrm{G}_{\text {HAP }}$ over time in acid conditions.

The $\mathrm{pH}$ of the medium and the type of filler determine the release rate of the ions ${ }^{7}$, altering materials' mechanical properties. HAp is soluble in acid solutions ${ }^{9}$, insoluble in alkaline solutions, and distilled water, while $\alpha$-TCP and OCP are more soluble than HAp at neutral $p H^{9}$. Even so, there were no differences for $G_{C t r l} G_{O C P,}$ and $G_{a-T C P,}$ depending on the storage media. The rationale for that may be a better distribution of OCP and $\alpha$-TCP within the polymer, leading to lower $\mathrm{CaP}$-resin interfaces to be exposed and to react with lactic acid. Another important factor related to the solubility of CaP is the size of the particles, in which the decrease to a nanoscale level can increase their dissolution ${ }^{35}$. Furthermore, CaP stability decreases with the increase of impurities' presence $^{9}$ and the method used to synthesize the HAp ${ }^{24}$ leads to the presence of carbonates in the final powder, which may have favored its dissolution?.

Here we observed the different behavior of bioactive resin-based restorative materials depending on the type of CaP incorporated into them. Interestingly, the physical response of the materials when facing various storing media depended on the $\mathrm{CaP}$ added. Therefore, further evaluations are encouraged in situ and in vivo to deeply understand the biological effects of these bioactive materials in patients with different risks of caries. 
In conclusion, the findings of this study showed that HAp, OCP, and $\alpha$-TCP affected the physical behavior of the experimental adhesive resins in different ways. HAp was the $\mathrm{CaP}$ that most adversely affected the surface roughness and the mechanical property of the material, mainly when exposed to an acid medium.

\section{Acknowledgments}

The authors gratefully acknowledge Microscopy and Microanalysis Center (Federal University of Rio Grande do Sul) for the transmission electron microscopy analysis. This study was financed in part by the Coordenação de Aperfeiçoamento de Pessoal de Nível Superior - Brasil (CAPES) - Finance Code 001 - scholarship. Conflicts of Interest: none.

\section{References}

1. Demarco FF, Corrêa MB, Cenci MS, Moraes RR, Opdam NJM. Longevity of posterior composite restorations: not only a matter of materials. Dent Mater. 2012 Jan;28(1):87-101. doi: 10.1016/j.dental.2011.09.003.

2. Glauser S, Astasov-Frauenhoffer M, Müller JA, Fischer J, Waltimo T, Rohr N. Bacterial colonization of resin composite cements: influence of material composition and surface roughness. Eur J Oral Sci. 2017 Aug;125(4):294-302. doi: 10.1111/eos.12355.

3. Ranjkesh B, Ding M, Dalstra M, Nyengaard JR, Chevallier J, Isidor F, et al. Calcium phosphate precipitation in experimental gaps between fluoride-containing fast-setting calcium silicate cement and dentin. Eur J Oral Sci. 2018 Apr;126(2):118-25. doi: 10.1111/eos.12399.

4. Jefferies SR, Fuller AE, Boston DW. Preliminary Evidence That Bioactive Cements Occlude Artificial Marginal Gaps. J Esthet Restor Dent. 2015 May;27(3):155-66. doi: 10.1111/jerd.12133.

5. Jang JH, Lee MG, Ferracane JL, Davis H, Bae HE, Choi D, et al. Effect of bioactive glasscontaining resin composite on dentin remineralization. J Dent. 2018 Aug 1;75:58-64. doi: 10.1016/j.jdent.2018.05.017.

6. Alania Y, Natale LC, Nesadal D, Vilela H, Magalhães AC, Braga RR. In vitro remineralization of artificial enamel caries with resin composites containing calcium phosphate particles. J Biomed Mater Res B Appl Biomater. 2019 Jul;107(5):1542-50. doi: 10.1002/jbm.b.34246.

7. Braga RR. Calcium phosphates as ion-releasing fillers in restorative resin-based materials. Dent Mater. 2019 Jan;35(1):3-14. doi: 10.1016/j.dental.2018.08.288.

8. Liang K, Gao Y, Xiao S, Tay FR, Weir MD, Zhou X, et al. Poly(amido amine) and rechargeable adhesive containing calcium phosphate nanoparticles for long-term dentin remineralization. J Dent. 2019 Jun;85:47-56. doi: 10.1016/j.jdent.2019.04.011.

9. Dorozhkin SV. Bioceramics of calcium orthophosphates. Biomaterials. 2010 Mar;31(7):1465-85. doi: 10.1016/j.biomaterials.2009.11.050.

10. Uskoković V, Uskoković DP. Nanosized hydroxyapatite and other calcium phosphates: Chemistry of formation and application as drug and gene delivery agents. J Biomed Mater Res Part B Appl Biomater. 2011 Jan;96B(1):152-91. doi: 10.1002/jbm.b.31746.

11. Garcia IM, Leitune VCB, Samuel SMW, Collares FM. Influence of different calcium phosphates on an experimental adhesive resin. J Adhes Dent. 2017;19(5):379-84. doi: 10.3290/j.jad.a38997.

12. Kavrik F, Kucukyilmaz E. The effect of different ratios of nano-sized hydroxyapatite fillers on the micro-tensile bond strength of an adhesive resin. Microsc Res Tech. 2019 May;82(5):538-43. doi: 10.1002/jemt.23197. 
13. Par M, Tarle Z, Hickel R, Ilie N. Mechanical properties of experimental composites containing bioactive glass after artificial aging in water and ethanol. Clin Oral Investig. 2019 Jun;23(6):2733-41. doi: 10.1007/s00784-018-2713-6.

14. Costa AR, Correr-Sobrinho L, Ambrosano GMB, Sinhoreti MAC, Borges GA, Platt JA, et al. Dentin bond strength of a fluoride-releasing adhesive system submitted to pH-cycling. Braz Dent J. 2014;25(6):472-8. doi: 10.1590/0103-6440201302445.

15. Schwendicke F, Al-Abdi A, Pascual Moscardó A, Ferrando Cascales A, Sauro S. Remineralization effects of conventional and experimental ion-releasing materials in chemically or bacterially-induced dentin caries lesions. Dent Mater. 2019 May;35(5):772-9. doi: 10.1016/j.dental.2019.02.021.

16. Roque ACC, Bohner LOL, de Godoi APT, Colucci V, Corona SAM, Catirse ABCEB. Surface roughness of composite resins subjected to hydrochloric acid. Braz Dent J. 2015 Jul;26(3):268-71. doi: 10.1590/0103-6440201300271.

17. Yoshihara K, Nagaoka N, Maruo Y, Sano H, Yoshida Y, Van Meerbeek B. Bacterial adhesion not inhibited by ion-releasing bioactive glass filler. Dent Mater. 2017 Jun;33(6):723-34. doi: 10.1016/j.dental.2017.04.002

18. Caldeira EM, Telles V, Mattos CT, Nojima MDCG. Surface morphologic evaluation of orthodontic bonding systems under conditions of cariogenic challenge. Braz Oral Res. 2019 Apr 25;33:e029. doi: 10.1590/1807-3107bor-2019.vol33.0029.

19. Cortopassi LS, Shimokawa CAK, Willers AE, Sobral MAP. Surface roughness and color stability of surface sealants and adhesive systems applied over a resin-based composite. J Esthet Restor Dent. 2020 Jan;32(1):64-72. doi: 10.1111/jerd.12548.

20. Reis A, Martins GC, de Paula EA, Sanchez AD, Loguercio AD. Alternative aging solutions to accelerate resin-dentin bond degradation. J Adhes Dent. 2015;17(4):321-8. doi: 10.3290/j.jad.a34591.

21. Montagner AF, Kuper NK, Opdam NJM, Bronkhorst EM, Cenci MS, Huysmans MCDNJM. Wall-lesion development in gaps: The role of the adhesive bonding material. J Dent. 2015 Aug;43(8):1007-12. doi: 10.1016/j.jdent.2015.04.007.

22. Thurmer MB, Vieira RS, Fernandes JM, Coelho WTG dos S LA. Synthesis of Alpha-Tricalcium Phosphate by Wet Reaction and Evaluation of Mechanical Properties. Mater Sci Forum. 2012;727728:1164-9. doi: 10.4028/www.scientific.net/MSF.727-728.1164.

23. Suzuki O, Miyasaka Y, Sakurai M, Nakamura M, Kagayama M. Bone Formation on Synthetic Precursors of Hydroxyapatite. Tohoku J Exp Med. 1991 May;164(1):37-50. doi: 10.1620/tjem.164.37.

24. Trommer RM, Santos LA, Bergmann CP. Nanostructured hydroxyapatite powders produced by a flame-based technique. Mater Sci Eng C. 2009 Aug;29(6):1770-5. doi: 10.4028/www.scientific.net/MSF.727-728.1164.

25. Briso ALF, Caruzo LP, Guedes APA, Catelan A, Dos Santos PH. In vitro evaluation of surface roughness and microhardness of restorative materials submitted to erosive challenges. Oper Dent. 2011 Jul;36(4):397-402. doi: 10.2341/10-356-L.

26. Lenzi TL, Calvo AFB, Tedesco TK, Ricci HA, Hebling J, Raggio DP. Effect of method of caries induction on aged resin-dentin bond of primary teeth. BMC Oral Health. 2015 Jul;15(1). doi: 10.1186/s12903-015-0049-z.

27. Collares FM, Ogliari FA, Zanchi CH, Petzhold CL, Piva E, Samuel SMW. Influence of 2-hydroxyethyl methacrylate concentration on polymer network of adhesive resin. J Adhes Dent. 2011;13(2):125-9. doi: 10.3290/j.jad.a18781.

28. Øilo M, Bakken V. Biofilm and dental biomaterials. Materials (Basel). 2015 Jun;8(6):2887-900. doi: $10.3390 / \mathrm{ma} 8062887$.

29. Quirynen M, Marechal M, Busscher HJ, Weerkamp AH, Darius PL, van Steenberghe D. The influence of surface free energy and surface roughness on early plaque formation: An in vivo study in man. $J$ Clin Periodontol. 1990;17(3):138-44. doi: 10.1111/j.1600-051X.1990.tb01077.x. 
30. Yang S-Y, Kwon J-S, Kim K-N, Kim K-M. Enamel Surface with Pit and Fissure Sealant Containing 45S5 Bioactive Glass. J Dent Res. 2016 May;95(5):550-7. doi: 10.1177/0022034515626116.

31. Tjäderhane L, Nascimento FD, Breschi L, Mazzoni A, Tersariol ILS, Geraldeli S, et al. Strategies to prevent hydrolytic degradation of the hybrid layer-A review. Dent Mater. 2013 Oct;29(10):999-1011 doi: 10.1016/j.dental.2013.07.016.

32. Shah MB, Ferracane JL, Kruzic JJ. Mechanistic aspects of fatigue crack growth behavior in resin based dental restorative composites. Dent Mater. 2009 Jul;25(7):909-16. doi: 10.1016/j. dental.2009.01.097.

33. Palaniappan S, Bharadwaj D, Mattar DL, Peumans M, Van Meerbeek B, Lambrechts P. Nanofilled and microhybrid composite restorations: Five-year clinical wear performances. Dent Mater. 2011 Jul;27(7):692-700. doi: 10.1016/j.dental.2011.03.012.

34. Hemingway CA, Shellis RP, Parker DM, Addy M, Barbour ME. Inhibition of hydroxyapatite dissolution by ovalbumin as a function of $\mathrm{pH}$, calcium concentration, protein concentration and acid type. Caries Res. 2008 Sep;42(5):348-53. doi: 10.1159/000151440.

35. Dong Z, Li Y, Zou Q. Degradation and biocompatibility of porous nano-hydroxyapatite/polyurethane composite scaffold for bone tissue engineering. Appl Surf Sci. 2009 Apr 1;255(12):6087-91. doi: 10.1016/j.apsusc.2009.01.083. 